\title{
New doubts over rock-dating techniques
}

[SAN DIEGO] The rock-dating techniques developed by a geographer at Arizona State University (ASU) have again been called into question as a detailed analysis published last week strongly suggested that some of the results may have been fabricated.

The dating method devised and used by ASU's Ronald I. Dorn was shown to be largely meaningless in an article published in Science by researchers from four institutions, including the University of Arizona in Tucson.

In an accompanying rebuttal, Dorn acknowledged that his method for dating rock surfaces was fundamentally flawed. But he denied any impropriety, calling the suggestions of sample content manipulation "utterly false".

After the publication of the Science article, a geologist from a fifth institution - John W. Bell of the University of Nevada at Reno told Nature that he had discovered the same type of irregularities with Dorn's work as had been identified by the Arizona-led group.

Bell's discovery, involving rock varnish samples for a research project near the proposed Yucca Mountain nuclear waste site in Nevada, seem to provide independent confirmation of the findings of the Arizona-led group, raising further questions about the credibility of Dorn's research.

"We are worried about the scientific integrity of the work [Dorn did for us]" said Bell. "If there is any bad data, we want to make sure we weed that out." He said that excluding Dorn's data is not expected to change the results of his study, which examined the age of an earthquake near the waste site.

Dorn's method involves scraping varnish

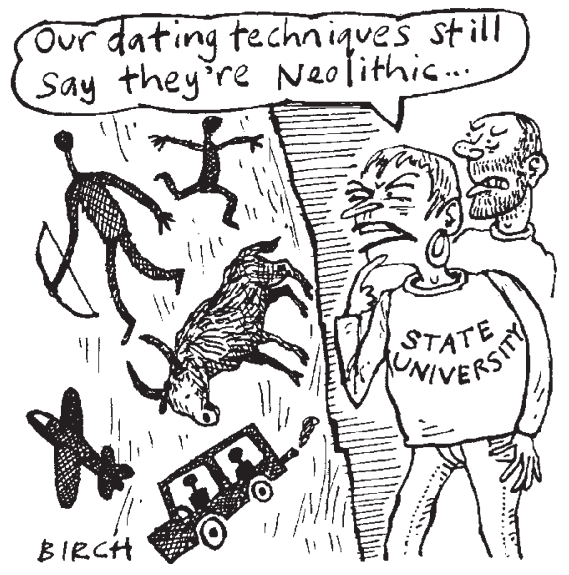

off a rock surface, treating this sample, and then analysing the remaining substance using accelerator mass spectrometry (AMS) to determine its age. Working with scientists around the world, Dorn has dated surfaces near rock art in the United States, Australia and Portugal, and used the same method for an earlier published study on rock formation age near Yucca Mountain.

The article in Science revealed that an analysis by two AMS laboratories found pieces of coal and/or charcoal-like material in about 80 of Dorn's samples from previous projects. The coal and charcoal have widely disparate radiocarbon dates, say the scientists, who also are from Columbia University's Lamont Doherty Earth Observatory, Northern Arizona University and Eidgenössische Technische Hochschule in Switzerland.

"If you have a sample mixture of two different ages, it will not yield a reliable age, just a measure of a ratio for the age of the two com-

\section{German institute 'correct' to fire technician}

[MUNICH] An investigation into a case of scientific fraud at the Max Planck Institute for Plant Breeding in Cologne has endorsed the institute's decision to dismiss both a technician who admitted manipulating experiments and the leader of her research group, Richard Walden, who accepted overall responsibility (see Nature 393, 293; 1998).

The investigation committee presented its report on the affair, which continued for six years, at the annual meeting of the Max Planck Society (MPS) in Weimar last week. But the report also concludes that Jeff Schell, the director of the institute's department of plant genetics in which the experiments were carried out, did not neglect his duty of ensuring good scientific practice.

Furthermore, Schell's authorship of many of the papers in question could not be regarded as merely honorary, says the report, as he made a significant intellectual contribution to the design of experiments and discussion of their results. New MPS rules frown on honorary authorship.

Crucial experiments in the papers under suspicion, published in high-profile journals including Nature and Science, were repeated during the four-month investigation. The report has been sent to the external chairman of the investigation committee, Walter Odersky, a former president of the German constitutional court, and Hildegund Holzheld, president of the Bavarian constitutional court, who have been asked to judge if any issues have been left open.

The MPS committee on good scientific practice is considering what lessons can be learnt from the case. "We want to encourage more openness between scientists of an institute, so that new results are widely discussed to the point where experiments could be repeated [for confirmation] by colleagues," says Hubert Markl, president of the MPS. ponents," says J. Warren Beck, a University of Arizona geochemist and a lead author of the Science article. Beck and colleagues found no coal or charcoal in rock varnish samples they collected and analysed to try to duplicate Dorn's work.

After first making the unusual discovery in 1996, the University of Arizona scientists reported the findings to the National Science Foundation (NSF), which funds both their AMS laboratory and Dorn's research. Officials say that the NSF then subpoenaed Dorn's samples from the University of Arizona, and ASU began an inquiry into whether Dorn had committed scientific misconduct by altering the samples with coal and/or charcoal to fabricate dates.

But the probe dragged on until details of the dispute were published in Nature (392, 218 ; 1998) earlier this year. ASU officials in Phoenix then began interviewing Arizona scientists involved in the controversy. No administrators from ASU, Arizona or the NSF would discuss the current status of the Dorn inquiry.

In his rebuttal, Dorn insists that coal and charcoal occur naturally in rock varnish, writing "my results have been fully replicated by others". In particular, Dorn cites an unpublished article by ASU geologist J. Ramon Arrowsmith, who Dorn writes "replicated in an independent study" his work after being "trained in sample collection and preparation procedures".

But in an interview last week, Arrowsmith denied that his article replicates Dorn's rockvarnish method. Arrowsmith says he used a different technique to look for organic material in "the contents of cracks" in rocks, that no AMS dating tests were performed on the sample, and that he wasn't trained by Dorn to use his established method of dating rock varnish. Arrowsmith described his project, started last autumn, as "a quick way" of trying to "show these particles could be found" in rock.

Scientists at the University of Arizona and Nevada remain sceptical about Dorn's claim of finding the organic material in the rock varnish, because the coal and charcoal-like pieces identified were so large. The Arizona scientists say they found pieces as large as 1 $\mathrm{mm}$ across. Bell said that a microscopic examination of 5 of the 15 Nevada samples which were analysed at the Rafter Radiocarbon Laboratory in New Zealand - also found pieces of this size. Noting that the rock varnish was only $0.2 \mathrm{~mm}$ thick in the Nevada research, Bell said: "I have not heard any reasonable explanation of how particles that size could be extracted from such thin varnish."

Bell said that Dorn has refused to let him retrieve the Nevada samples from New Zealand for more analysis. Dorn was unavailable for comment, reportedly on a field trip.

RexDalton 